Brit. J. vener. Dis. (1963), 39, 139.

\title{
TESTS OF CURE IN TREATED EARLY AND LATENT SYPHILIS*
}

\author{
BY \\ F. J. G. JEFFERISS \\ St. Mary's Hospital, London
}

To show accurately and statistically the end results of therapy of a large number of cases of syphilis treated with penicillin is unfortunately hardly possible in Great Britain, where a patient is free to come and go as he wishes, because of the natural tendency to default from long observation. The best that can be done is to collect and evaluate one's experiences after following for many years as many patients as possible for as long as they will permit. In that way, if the numbers are great enough and the time sufficiently long, conclusions can eventually be reached which, because they have stood the test of time, are as valid or better than those collected by the more usual statistical methods carried out over a shorter period. As 19 years have passed since penicillin was first used in the treatment of syphilis, the long-term result of this therapy can now be evaluated in its own right, and the necessary tests of cure can be decided upon without depending on the knowledge gained with very different drugs in the years between the two world wars.

\section{Material and Results}

Early syphilis includes cases of primary and secondary syphilis and those patients with very early latent disease who have not been infected for more than one year. The latter diagnosis is one in which, unless great care is taken, it is easy mistakenly to include, as cases of early latent syphilis, patients who have been infected for longer than a year, and it is therefore advisable to exclude any case from this category if there is any reasonable possibility that the disease is of more than one year's standing.

In the years 1946 to 1961, 2,208 cases of early syphilis were diagnosed and treated at St. Mary's Hospital (Figure, overleaf).

Added to these new cases were many others who,

* Based on a Presidential Address to the M.S.S.V.D., given on October 26, 1962. having been treated elsewhere, especially in the armed forces, came to this hospital for continuation of treatment or tests of cure. From 1946 to 1951 our patients were treated with neoarsphenamine and/or bismuth as well as penicillin (McElligott, Jefferiss, and Willcox, 1948; Jefferiss, Willcox, and McElligott, 1951), and since 1951 further cases have been treated with penicillin only. The penicillin course now given by me comprises ten daily injections of $1,200,000$ units procaine penicillin. In the early years a much smaller dose, 600,000 units penicillin daily for 8 days, was used, but the dose has since been raised to its present level rather to follow trends elsewhere than because of any local failure. The dose has always been well above the minimum curative level stipulated by Mahoney, Arnold, and Harris (1943) in their original work $(1.2$ million units in divided doses given over 5 days).

The follow-up period and tests of cure of early syphilis generally agreed upon in the years between the wars were based on the experience gained with treatment with neoarsphenamine and bismuth. Under that regimen the period of observation was at least 2 years, with monthly blood tests for 6 months, followed by quarterly tests for the remainder of that time, the cerebrospinal fluid being examined as nearly as possible one year after treatment. In spite of the great improvement in the results of therapy, this routine is still advised by many venereologists (King, 1959). However, my experience here, and previously during the war with large numbers of cases of early syphilis in the Royal Air Force, soon made me realize that treatment with penicillin was very much more efficient than with neoarsphenamine and bismuth. I can say without any hesitation that during those 19 years $I$ have never known a case of early syphilis treated with a minimum total dose of 2.4 million units penicillin spread over 8 days which failed to respond to treatment or which relapsed thereafter. Any cases that $I$ have re-treated have in my judgment proved to be re-infections. 


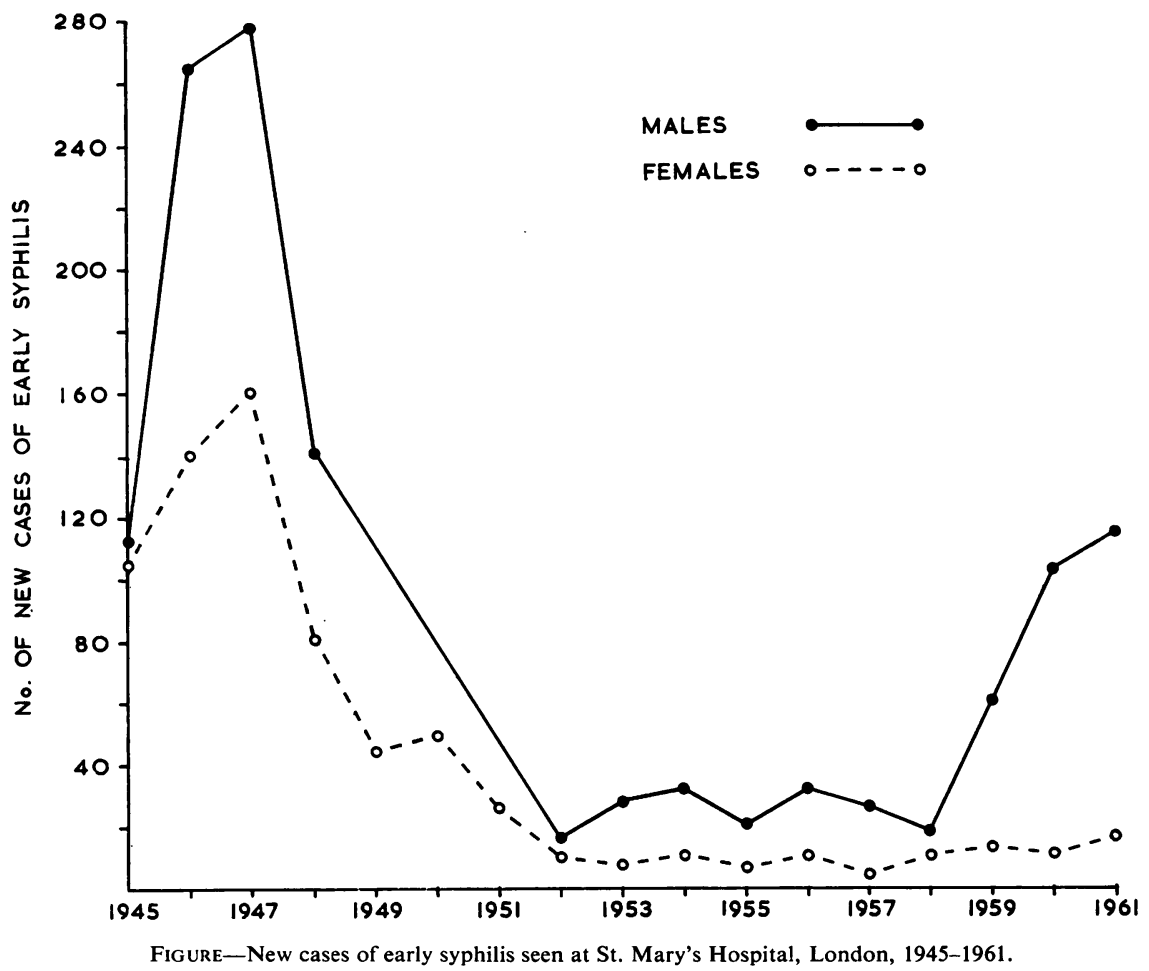

Early syphilis is becoming largely a disease of the homosexual (Jefferiss, 1956). At least 72 per cent. of the 116 male cases of early syphilis seen at St. Mary's in 1961 had been infected by homosexual contact, and it appears that the position is similar elsewhere (Nicol, 1960). Males have formed 90 per cent. of the total cases here in recent years (Figure), and it is now very rare to find a male patient with secondary syphilis who has not been infected ano-rectally. When attempting to decide whether a case is a relapse or a re-infection, it is, therefore, of little value to put much reliance on the absence or presence of a penile chancre. The promiscuous passive homosexual is in greater danger than the heterosexual of having the diagnosis of early syphilis missed and of going on to develop the later manifestations of the disease, because of the common failure by physicians to take into account the anus or rectum as a possible site of entry of infection.

The outcome of 636 cases of syphilis treated solely with penicillin at St. Mary's Hospital, London, is described in another paper (Jefferiss and Willcox, 1963). It will be seen that, in the post-treatment observation period, except of course in those patients who were reinfected, the Wassermann (Harrison-Wyler's modified method) titres had fallen to at most weakly positive by the end of 3 months and to complete negativity by the 6th month. The Harris (V.D.R.L.) test and also the Reiter protein complement-fixation test, which has been carried out latterly, also became negative by the 6th month in all but two primary cases and most secondary cases, but they tended to remain weakly positive in a few cases of late secondary and early latent syphilis up to the end of one year or even longer. I have no doubt that the treponemal immobilization test and other very sensitive tests would remain positive for as long or longer. However, I do not think that we should concern ourselves overmuch in a treated case, in the absence of clinical signs of relapse, with the results of the more delicate serological tests which show that a mimimal quantity of antibodies to syphilis still remain. The antibody titre in typhoid fever remains raised for many years after the illness has disappeared, but experience has shown that the patient does not continue to suffer from the disease, is not an asymptomatic carrier, and will not relapse. Our findings at St. Mary's Hospital are similar to the results of an investigation into the outcome of treatment solely with penicillin of 1,868 Royal Air Force patients suffering from primary and secondary syphilis in 1945 and 1946, which has been carried out 
recently and is to be published. I am informed that, of these 1,868 cases, 301 were kept under observation for 2 or more years and had all become sero-negative by the end of that time.

Also, Hellerström and Skog (1961) reported on 91 cases of primary and secondary syphilis followed for from 3 to 11 years after penicillin treatment, with no failures or relapses.

\section{Discussion}

As stated above, my experience over the last 19 years has shown that early syphilis which has been treated adequately with penicillin does not relapse clinically or serologically. The lesions in cases treated with subcurative doses of the antibiotic heal temporarily, only to break out again in less than a month. It is, therefore, my opinion that in fully-treated cases of early syphilis a follow-up period of one year is sufficient, during which time clinical examinations should be made and serological tests carried out each month to ensure that the Wassermann test becomes and remains negative on repetition and that the more sensitive tests become at most very weakly positive. In the very rare cases in which the Wassermann test remains positive for longer than 6 months, the patient should be kept under observation until it has become negative and has remained so for 6 months, which will almost certainly be within one year from treatment. A followup period of one year is now advised by the U.S. Public Health Service.

\section{Cerebrospinal Fluid Examination}

Having carried out cerebrospinal fluid examinations by the hundred during the latter part of the war in the Royal Air Force, and afterwards in civilian life, on patients who had been treated for early syphilis with penicillin, I have found that the results after one year turned out to be normal in every fully-treated case. The C.S.F. findings in a series of 160 cases treated with penicillin, bismuth, and sometimes neoarsphenamine as well, have been described (Jefferiss and others, 1951). The results showed no significant abnormality except in two cases in which there were some isolated and unexpected changes in the cerebrospinal fluid after treatment. We were doubtful of their significance at the time, as the only questionable feature in one was a cell count raised to 6 lymphocytes per cu. $\mathrm{mm}$. and the only abnormality in the other occurred in the Lange curve findings. It is now generally agreed that one abnormal result in the various C.S.F. investigations, without support from the others, is suspect, and I therefore think that these two cases are not significant exceptions and may be ignored.
In the recent paper on patients seen at St. Mary's who had been treated with penicillin only (Jefferiss and Willcox, 1963), the results of 82 C.S.F. examinations are described. All were normal apart from one in which the only possible abnormality was a total protein of $40 \mathrm{mg}$. and a Lange curve of 1111000 .

In the Royal Air Force investigation mentioned above, I understand that the cerebrospinal fluids of 378 patients were examined between 1 and 2 years after treatment and were all found to be normal. In the series of Hellerström and Skog (1961), 51 cases had cerebrospinal fluid examinations and were all normal. Added together, these amount to 511 cerebrospinal fluid examinations of cases of early syphilis treated with penicillin only. Adding the 160 cases treated with bismuth and sometimes neoarsphenamine as well, the total number of fluids tested comes to 671 , and only three of these showed slight, probably insignificant, deviations from the normal. I have never seen a case of early syphilis properly treated with a reliable penicillin which has later developed a significantly abnormal cerebrospinal fluid, neurosyphilis, or any form of late syphilis.

Hahn, Lewis, Wiggall, and Cross (1951) have shown that, in early asymptomatic neurosyphilis, progression does not occur after penicillin therapy.

I have, therefore, come to the conclusion that the cerebrospinal fluid examination is entirely irrelevant and unnecessary as a test of cure in a case of early syphilis fully treated with penicillin, providing that the blood Wassermann reaction has become and has stayed negative for 6 months by the end of one year after treatment. A cerebrospinal fluid examination is not one to be undertaken lightly as there are serious risks attached to it, such as meningeal infection and collapse due to medullary conus impaction, as well as the severe headache which often seems to be an unavoidable sequel (Rosedale, 1956; Schofield, 1957). To submit a young working person, or anyone for that matter, to such a test of cure for early syphilis is, in my opinion, now quite unjustifiable, in view of the experience which we have now gained in treating the disease with penicillin.

\section{Latent Syphilis}

In latent syphilis (i.e. syphilis that has been detected by positive blood tests, sometimes with positive cerebrospinal fluid findings, but with no physical signs of disease), my experience suggests that, once treatment has been given and the serological tests have shown a constant tendency to become more weakly positive, it is pointless to continue observation for more than 2 years. Prolonged observation or re-treatment will not prevent the occurrence of late manifestations of the disease, 
such as neurosyphilis or cardiovascular syphilis, if they have not already been eliminated by the original treatment, but may well set up a severe chronic anxiety state. The odd chance of detecting an early aneurysm, which might possibly be operable, hardly justifies keeping patients in suspense for years. I have recently seen cases of men, who were diagnosed when young as having latent syphilis, congenital or acquired, and had been thoroughly treated for it with penicillin 10 or more years ago, kept under observation ever since, often in misery and suspense, having had repeated blood tests with weakly positive results, and the added unpleasantness of several cerebrospinal fluid examinations, the results of which were, of course, negative. Sometimes an extra course of treatment was given in a vain attempt to make the persisting positive serology negative. Surely this type of management is not in the best interests of the patient, except of course those, usually of the older generation, who are only reassured by regular visits to the venereologist, for the old theory of the incurability of syphilis dies hard. It would seem that the observation period of a case of latent syphilis should be limited to about 2 years, as during that time any possible therapeutic paradox will have become evident and the serological pattern will have confirmed the suspected stage of the disease. Re-examination of the cerebrospinal fluid is unnecessary once the cell count has become normal and the other findings have shown a marked tendency to revert to negativity.

Although I have given the opinion that the posttreatment observation of syphilis may now be simplified and shortened, I do not wish in any way to suggest that it is a less serious disease than formerly, or that anything of my observations apply to the later manifestations of syphilis, where we are not only dealing with an infection but with the permanent damage it has done. Thomas (1954) stated that "early acute syphilis represents a different clinical and immunologic disease than late syphilis". Syphilis should be searched for and managed with as much, or even greater, care than before, as signs may now very easily be suppressed temporarily by small doses of antibiotics given for other purposes. The end results of a neglected case are as terrible as they have ever been, for, as we all know, even penicillin will not repair aortic aneurysms or replace a damaged nervous system.

\section{Summary and Conclusions}

As the result of experience gained over the last 19 years in the treatment with penicillin of more than 2,200 cases of early syphilis and 1,600 cases of latent syphilis at St. Mary's Hospital, London, and of other cases previously treated in the Royal Air Force, the author gives the following personal opinions:

(1) That the observation period after treatment of early syphilis may safely be limited to one year in most cases;

(2) That, as in his experience the cerebrospinal fluid is never significantly abnormal when examined after full penicillin treatment of early syphilis, this is no longer necessary as a test of cure of the disease.

(3) That the post-treatment observation of latent syphilis should usually be limited to about 2 years, the doubtful value of longer observation being often outweighed by the ill-effects of prolonged anxiety, especially on the younger patients.

\section{REFERENCES}

Hahn, R. D., Lewis, B. I., Wiggall, R. H., and Cross, E. S., Jr. (1951). Amer. J. Syph., 35, 433.

Jefferiss, F. J. G. (1956). Brit. J. vener. Dis., 32, 17.

—, Willcox, R. R., and McElligott, G. L. M. (1951). Lancet, 1, 83.

King, A. J. (1959). Brit. med. J., 1, 355.

McElligott, G. L. M., Jefferiss, F. J. G., and Willcox, R. R. (1948). Brit. J. vener. Dis., 24, 45.

Mahoney, J. F., Arnold, R. C., and Harris, A. (1943). J. vener. Dis. Inform., 24, 355.

Nicol, C. (1960). Practitioner, 184, 345.

Rosedale, N. (1956). Brit. J. vener. Dis., 32, 127.

Schofield, C. B. S. (1957). Ibid., 33, 30.

Thomas, E. W. (1954). Clin. Med., 61, 611.

Willcox, R. R., Jefferiss, F. J. G., and McElligott, G. L. M. (1958). Brit. J. vener. Dis., 34, 14.

Contrôle des résultats du traitement de la syphilis précoce et latente

\section{RÉSUMÉ}

L'emploi pendant 19 ans de la pénicilline dans plus de 2.200 cas de syphilis précoce et de 1.600 cas de syphilis latente à St. Mary's Hospital, London, et aussi dans plusieurs cas parmi le personnel de la Royal Air Force, suscite les remarques suivantes:

(1) Une année de surveillance après le traitment de la syphilis précoce suffit dans la plupart des cas.

(2) Puisque le liquide céphalo-rachidien n'est jamais anormal après l'administration de la pénicilline en quantité suffisante, ce procédé n'est pas nécessaire comme test de guérison.

(3) La surveillance de la syphilis latente ne doit durer que 2 ans, parce que les mauvais effets d'une inquiétude prolongée l'emporteront sur la valeur de l'observation, surtout chez les jeunes malades. 